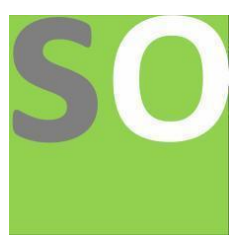

Article title: Perinatal Exposure to low Protein Diets Perturbs some Ovarian Genes Critical to Reproductive Health from One Generation to Another

Authors: Abey Nosarieme[1]

Affiliations: Department of Biochemistry, College of medicine, University of Lagos[1]

Orcid ids: 0000-0003-0779-7086[1]

Contact e-mail: nosariemeomoregie@gmail.com

License information: This work has been published open access under Creative Commons Attribution License http://creativecommons.org/licenses/by/4.0/, which permits unrestricted use, distribution, and reproduction in any medium, provided the original work is properly cited. Conditions, terms of use and publishing policy can be found at https://www.scienceopen.com/.

Preprint statement: This article is a preprint and has not been peer-reviewed, under consideration and submitted to ScienceOpen Preprints for open peer review.

DOI: 10.14293/S2199-1006.1.SOR-.PPAV6FU.v1

Preprint first posted online: 03 February 2021

Keywords: CEBPA, ER-alpha 


\title{
Perinatal Exposure to low Protein Diets Perturbs some Ovarian Genes Critical to Reproductive Health from One Generation to Another
}

\begin{abstract}
The maintenance of fertility status critically depends on the proper functioning of the ovary, which is also a reflect of normal development of ovarian follicles. Malnourished males and females have been scientifically proven to form a major infertile population in developing countries. Proper nutrition therefore forms a baseline for functional reproductive makeup. This study seeks to assess the mRNA expression level of ovarian inhibin alpha (IHA), Estrogen receptor (ER $\alpha$ ), Aromatase, CCAAT-enhancer binding protein alpha (CEBPA) and Fibroblast Growth Factor Receptor 1 (FGFR1) in the $F_{0}$ and $F_{1}$ rat progeny subjected to perinatal dietary protein deficiency. Rats in four (4) groups were fed different grade of protein deficient diets $(5 \%, 10 \%, 21 \%$ protein diets and rat chow). Total RNA was extracted from the snap frozen ovary excised from the different rat groups, checked for quality, converted the cDNA and RT-qPCR was used to quantify amount of each mRNA expressed in the tissue. Result shows severe alteration in the level of expression of some of the key genes assessed essential for sustenance of reproductive health from one generation to another. Inhibin alpha was downregulated while CEBPA was upregulated in 5\%PD groups at $\mathrm{F}_{1}$ and $\mathrm{F}_{2}$, ER $\alpha$ was downregulated only at first generation but normalized in the second generation. Aromatase in the $10 \%$ group was upregulated at $\mathrm{F}_{1}$ and $\mathrm{F}_{2}$ generation, while in the 5\%PD, it was downregulated only at $\mathrm{F}_{2}$. These modulations mediate the effects of dietary protein deficiency on the ovarian and reproductive function from one generation to another.
\end{abstract}

Keywords: Protein-deficiency, Ovary, CEBPA, Inhibin- $\alpha$, Aromatase, gene expression, ER $\alpha$, FGFR1,

\section{Introduction}

Reproductive health is essential for social, economic and human development. Maternal diets and diets during early life may impact phenotype, as inappropriate nutrition is a pointer to programming effects in adulthood (Carlin et al., 2019). Protein ingestion is necessary for most biological processes, dietary protein deficiency has been a major malnutrition of concern in public health. Reproductive progress in mammals is dependent on nutritional status (Kaczmarek et al., 
2016), and the overall health status is reflective of previous experiences that occurred in earlier life phases. Follicular development and ovulation are key events on which adolescent reproductive health depends (Jo et al., 2004). Ovarian research in recent times has tried to identified downstream hormone-response genes that underlies the mechanisms in reproductive health and how environmental factors could impact it.

The regulation of gonadal function and sexual behavior is centered on the proper works of hormonal systems which is triggered by the hypothalamic circuitry. One of the major dynamics to reproductive health is a fully staged and unaltered folliculogenesis, which involves selection, recruitment, dominance, and ovulation. Follicles basically functions to produce mature oocytes for the propagation of the species and to synthesize the estrogens that support sexual responses (Duque-Guimarães et al., 2013). The survival of granulosa cells and theca cells which are fundamental units of the ovary are also very important in folliculogenesis. Abnormal folliculogenesis in early life (neonate) can lead to the disruption of ovarian function in adult life (Puttabyatappa \& Padmanabhan, 2018). The aim of the present study is to assess modulatory effects of early life dietary protein deficiency on some selected genes of fundamental functions in reproductive health, which include Aromatase, Estrogen receptor alpha, Inhibin-alpha, CCAAT enhancer binding protein-alpha and fibroblast growth factor receptor 1.

The aromatase complex is composed of a specific glycoprotein, cytochrome P450 (P450arom), and a ubiquitous flavoprotein forming the enzyme that is encoded by a single copy gene, cyp19 (Galmiche et al., 2006). Aromatase expression is very necessary for some developmental reproductive health and fertility, aberrant aromatase expression in tissues is usually associated with a number of pathological conditions (Zhao et al., 2016), as it acts in the terminal step of estrogen synthesis from androgens. The mechanism of estrogen action is predominantly through nuclear estrogen receptor (ER) expression in estrogen target organs (Mangelsdorf et al., 1995). Estrogen works through several possible cellular mechanisms to mediate its biological responses involving the receptors (Hamilton et al., 2017). Within the reproductive axis, inhibin is reported to have been a negative endocrine regulator of follicle stimulating hormone (FSH) release from the anterior pituitary. The granulosa cells of the ovary produce inhibin, and inhibin by each follicle increases as the granulosa cell population increases during normal follicle growth and maturation (Welt, 2004). Inhibin is applied in most clinical setting for fertility and reproductive function, it is 
recognized as the main peptide hormone that regulates FSH synthesis and secretion (Li et al., 2007). CCAAT enhancer-binding protein alpha (CEBPA) is a member of the bZIP family of transcription factors (Konopka, 2016), that are critical for normal cellular differentiation by transcriptional up-regulation of lineage-specific genes and function in a variety of highly differentiated tissues (Salvador et al., 2002). Fibroblast growth factor receptor 1 (FGFR1) is a member of the FGFR family, and it is a receptor tyrosine kinase that activates mitogen activated protein kinase signaling and phosphoinositide-3-kinase/AKT signaling (Shimizu et al, 2018). Aberrant expression and somatic mutation of FGFR1have been reported in several cancers. The expression profile of these genes will expose proper documentation of the resultant effects of the protein deficiency, which can then serve knowledge for therapeutic intervention especially in the reproductive health.

\section{Methods:}

All animal experiments were conducted in accordance to the ethics guidelines of health research Act 2004 on animal experimentation, validated and approved by the Health Research Ethics Committee in Animal Experiment of College of Medicine University of Lagos (local HREC; REC 11, Nigeria), with approval number: CMUL/HREC/11/18/462).

Seven/eight-weeks-old female Sprague-Dawley rats weighing averagely $170 \mathrm{~g}$ were maintained under standard housing conditions $\left(24 \pm 2{ }^{\circ} \mathrm{C}, 12 \mathrm{~h}\right.$-light/dark cycle and fed ad libitum. Rats were acclimated to the local environment conditions for one (1) weeks, after which experimental feeding continued.

Non-purified isocaloric diet was formulated, to ration the various protein percentage of the groupings (severely deficient group received 5\% protein diet, mildly deficient group received $10 \%$ protein diet, $21 \%$ protein diet (Markup for physiological status) and control diet (containing DRI percent for rat). The diet was formulated using non-purified constituents and standard formula, scored to requirements following adaptation from New Non-purified Diet (NTP-2000) for Rodents by Ghanto Rao, 1997). 


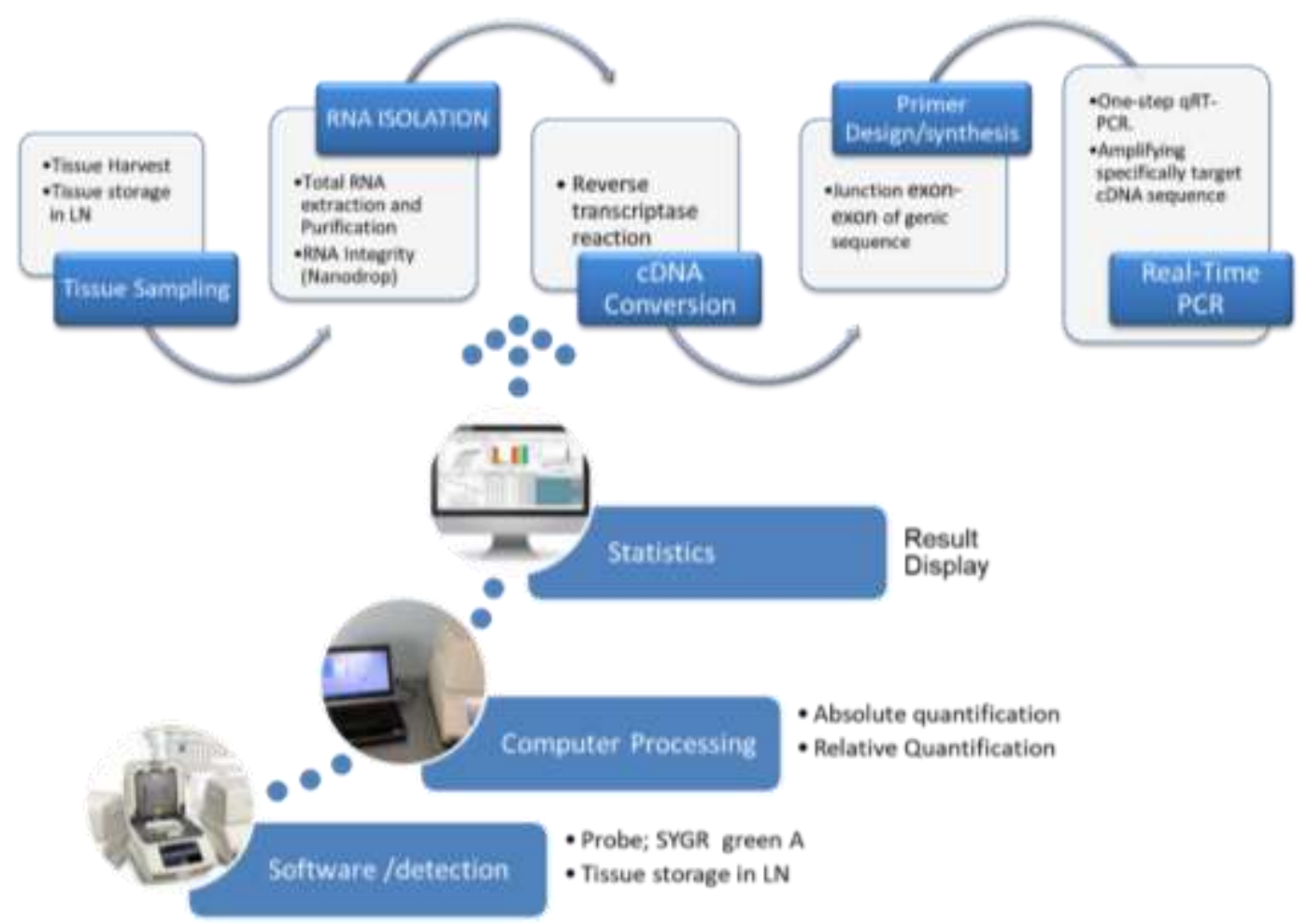

Fig: Schematic illustration of experimental design

Mating: Already certified reproductive males were used only as breeders in timed-mating of the females to generate offspring in generations used for the experiments. Breeding involves charting vaginal cytology three (3) weeks pre-breed, to establish cycle pattern, gestation day0 was established following the presence of sperm in the vaginal smear. Confirmed pregnant dams were separated to produce $F_{1}$ generation, this process was repeated for $F_{1}$ generation to produce $F_{2}$ generation while the different diet group feeding continues. At postnatal day 30, weaning and sex separation was carried based on the measured anogenital distance. The female pups from each generation was maintained on their group diets for further investigation.

\section{Gene Expression Profiling}

\section{Total RNA Extraction}


At 16 weeks of age, the female progenies were sacrificed by cervical dislocation between $8^{\text {th }}$ and $11^{\text {th }}$ hour, ovaries were removed and placed into RNAlater, snap frozen immediately in liquid nitrogen, and stored at $-80^{\circ} \mathrm{C}$ temperature for analysis. The experiment aimed at determining the mRNA expression levels of ovarian Inhibin- $\alpha$, Estrogen Receptor alpha (ER $\alpha)$, Fibroblast growth Factor Receptor 1(FGFR1), Aromatase and CCAAT Enhancer Binding protein alpha (CEBPA) in different percentage protein diet groups. The ovaries of at least 5 littermates were pooled to yield a representative litter sample for analysis, and total RNA was extracted using quick - RNA ${ }^{\mathrm{Tm}}$ miniprep (catalog R10548/R01055) Zymo research. Mechanical homogenizing was done, centrifuged (using Eppendorf centrifuge 5424) at 10,000rpm for 1minute to remove the debris. Total RNA was further purified by a RNeasy kit (QIAquick PCR purification kit, QIAGEN, Valencia CA), following manufacturer's instruction. The eluted RNA from the Zymo-spin column was kept at $-80^{\circ} \mathrm{C}$ for further analysis.

\section{Assessment of Total RNA Quality}

The purity of extracted RNA was carried out by measuring the optical density (OD) at different wavelengths. Nanodrop spectrophotometers (Thermo scientific, USA) was used to ascertain the purity and concentration of the extracted RNA, taking the absorbance at 280, 260 and 230nm. Nucleic acids absorb maximally at $260 \mathrm{~nm}$ whereas proteins have their maxima at $280 \mathrm{~nm}$. Also, contaminant and the background absorption were measured at 230nm. Samples with the ratio A260:A280 and A260:A230 between 1.80 and 2.20 were considered to be pure i.e not contaminating reverse transcriptase or DNA polymerase inhibitors. The integrity of the RNA was assessed by electrophoresis of the RNA samples, bands were detected via laser-induced fluorescence measurement (Chaumontet et al., 2015). RNA integrity was confirmed by ethidium bromide staining in an Agarose gel electrophoresis; with the Agilent 2100 Bioanalyzer (Agilent Technologies, USA).

\section{RT-qPCR Analysis}

\section{cDNA Conversion}

Reverse transcription was carried out on $300 \mu \mathrm{g}$ of the total RNA extracted made up to a final volume of $10 \mu \mathrm{l}$ using NEW England Biolabs Inc. One Taq One-step RT-PCR kit, following manufacturer's instruction, after which a 1:10 dilution of the cDNA product was prepared for use 
in subsequent steps. Briefly, RNA was denatured with oligo (dT) at $65^{\circ} \mathrm{C}$ for 5 minutes and then single strand cDNA was synthesized at $42^{\circ} \mathrm{C}$ for $1 \mathrm{hr}$ in a mix containing $2 \mu \mathrm{l}$ reverse transcriptase $(\mathrm{M}-\mathrm{MuLV}-\mathrm{RT}) \mathrm{mix}$, and $10 \mu \mathrm{l} 2 \mathrm{X}$ reverse transcription reaction mix. The enzyme was inactivated at $80^{\circ} \mathrm{C}$ for 5 minutes in order to bring the reaction to a halt. cDNA was stored at $-20^{\circ} \mathrm{C}$ and diluted 5-10 times in sterile milli-Q water. Prepared cDNA concentration was normalized to represent the same amount reverse transcribe total RNA in each sample.

\section{Quantitative PCR}

mRNA concentration of genes of interest were quantified by qPCR real time, this is to validate the relative change in gene expression in the ovary, induced by exposure to restricted amount of dietary protein intake. qPCR was done on the CFX connect Real-Time system (Applied Biosystems)), using GAPDH, as the reference gene. The Real time qPCR was carried out in a 384-well thermal block with the Luna Universal SYBR Green qPCR master mix (New England Bioloabs). The primer sequences of target genes, were designed as presented below. Preliminary experiments were carried out with to determine specificity of the primer. Reaction was performed in duplicate under the following thermocycling conditions: 60 seconds at $95{ }^{\circ} \mathrm{C}$ for initial denaturation and then $40-45$ cycles of $15 \mathrm{~s}$ at $95^{\circ} \mathrm{C}, 30 \mathrm{~s}$ at $60^{\circ} \mathrm{C}$ and $30 \mathrm{~s}$ at $72{ }^{\circ} \mathrm{C}$. Standard curve was generated for each primer set using serial dilutions of cDNA (The control, NTC (no template control), produced no amplification.). Relative expression values were normalized to mRNA level of GAPDH. The automated machine method generated the boxplot, showing the relative expression levels in each group.

Primer Design: Primer design software program was used to design the gene specific primer, to ensure that primers are specific for the target sequence and free of internal secondary structure, avoiding any form of complementary hybridization at 3'- ends within each primer and with each other. Primers were designed for the PCR experiment using the following standard. The length of the primer ranged from 18-25 nucleotides with a $>50 \%$ guanine/cytosine $(\mathrm{GC})$ in order to have a melting temperature $(\mathrm{Tm})$ from $50-65^{\circ} \mathrm{C}$. The web-based software Net Primer (http://www.premierbiosoft.com/netprimer/) was used to check and avoid the secondary structure, hairpin, primer dimmer. 
Table 1: Nucleotide Sequence of Specific Primers

\begin{tabular}{|c|c|c|c|}
\hline$S / N$ & Gene & Forward Primer & Reverse Primer \\
\hline 1 & $\begin{array}{l}\text { ERa (Estrogen } \\
\text { Receptor Alpha) }\end{array}$ & 5'-TATGGGGTCTGGTCCTGTGA-3' & 5'-TCGTATCCCGCCTTTCATCATG -3' \\
\hline 2 & AROMATASE & 5'-TCATGAAAGCTCTGACGGC-3' & 5'-CCCCAGGAAGAGCGCGTGTTAG-3' \\
\hline 3 & FGFR1 & 5'-GATGTGCAGAGCATCAACTGG-3' & 5'- TGGCAGTGCATCTGAGACATT-3' \\
\hline 4 & INHIBIN ALPHA & 5' - CTTTTCCCAGCCACAGGTGC-3' & 5' - AGCAGGGGCCTAGAGCTATT-3' \\
\hline 5 & GAPDH & 5'-GTTACCAGGGCTGCCTTCTC-3' & 5'-ACCAGCTTCCCATTCTCAGC-3' \\
\hline 6 & CEBPA & 5'- GGGTTCTTAGCCCCTTGCTT-3' & 5'- AGTACACACAAGGCGGATGG-3' \\
\hline
\end{tabular}

\section{Statistical Analysis.}

Data were analyzed using diets as factors. Results are presented as the mean \pm SEM. ANOVA was used for the statistical analysis. The results were correlated to different clinicopathological parameters.

\section{Results}

The Extracted RNA was considered pure, with most of the $\mathrm{OD}_{260 / 280}$ ranging from 1.8 to 2.3 (Table 2). The bands of the gel on electrophoresis plate, snapped out (Fig 1), shows clear integrity of the extracted ovarian RNA. Fig 2 and 3 respectively shows the mRNA expression level of ovarian Aromatase at $\mathrm{F}_{1}$ and $\mathrm{F}_{2}$. The fibroblast growth factor FGFR1 in 10\%PD was upregulated while in 5\%PD was downregulated at $\mathrm{F}_{2}$, although $\mathrm{F}_{1}$ generation levels remain unaffected (Fig 4 and 5). Fig 6 and 7 shows that Inhibin- $\alpha$ was downregulated in the severely deficient group (5\%protein diet group) at both generations. The Estrogen receptor $\alpha$ mRNA in the ovary of $5 \%$ protein diet groups (Fig 8) was only downregulated at $\mathrm{F}_{1}$, while other group (10\%PD) at $\mathrm{F}_{1}$ and $\mathrm{F}_{2}$ (Fig 8 \&9) maintained normal expression with reference to GAPDH. The Upregulated CEBPA mRNA expression in F1 and F2 generations of the protein deficient ovary was displayed in figure 10 and 11 respectively. 
Table 2: Concentration Optical Density of Extracted RNA

\begin{tabular}{|l|l|l|l|l|}
\hline Sample ID & $\mathrm{OD}_{280}$ & $\mathrm{OD}_{260}$ & $\mathrm{OD}_{260 / 280}$ & $\begin{array}{l}\mathrm{CONC} \\
(\mathrm{ng} / \mathrm{ml})\end{array}$ \\
\hline $5 \% \mathrm{~F} 1$ & 13.479 & 5.649 & 2.39 & 539.1 \\
\hline $5 \% \mathrm{~F} 1$ & 12.0225 .560 & 6.560 & 1.83 & 480.9 \\
\hline $10 \% \mathrm{~F} 1$ & 13.303 & 6.046 & 2.2 & 558.3 \\
\hline $10 \% \mathrm{~F} 1$ & 14.880 & 6.234 & 2.39 & 595.2 \\
\hline $10 \% \mathrm{~F} 1$ & 12.192 & 6.096 & 2.00 & 548.2 \\
\hline $21 \% \mathrm{~F} 1$ & 42.715 & 20.738 & 2.05 & 1698 \\
\hline $21 \% \mathrm{~F} 1$ & 30.897 & 14.417 & 2.14 & 1235.9 \\
\hline $21 \% \mathrm{~F} 1$ & 32.051 & 16.781 & 1.91 & 1432.7 \\
\hline $\mathrm{CF} 1$ & 23.822 & 11.690 & 2.04 & 952.9 \\
\hline $\mathrm{CF} 1$ & 36.294 & 18.014 & 2.01 & 1451.8 \\
\hline $\mathrm{CF} 1$ & 28.843 & 16.024 & 1.89 & 1003.2 \\
\hline $5 \% \mathrm{~F} 2$ & 17.958 & 8.855 & 2.03 & 718.3 \\
\hline $5 \% \mathrm{~F} 2$ & 18.134 & 8.963 & 2.02 & 725.4 \\
\hline $5 \% \mathrm{~F} 2$ & 8.359 & 4.235 & 1.97 & 334.4 \\
\hline $10 \% \mathrm{~F} 2$ & 18.134 & 8.963 & 2.02 & 725.4 \\
\hline $10 \% \mathrm{~F} 2$ & 23.633 & 11.450 & 2.06 & 945.3 \\
\hline $10 \% \mathrm{~F} 2$ & 22.143 & 10.962 & 2.02 & 884.6 \\
\hline $21 \% \mathrm{~F} 2$ & 19.021 & 9.182 & 2.07 & 760.8 \\
\hline $21 \% \mathrm{~F} 2$ & 22.707 & 10.974 & 2.07 & 908.3 \\
\hline $21 \% \mathrm{~F} 2$ & 24.662 & 11.021 & 2.23 & 933.8 \\
\hline $\mathrm{CF} 2$ & 18.963 & 9.283 & 2.04 & 758.5 \\
\hline CF2 & 35.908 & 17.587 & 2.04 & 1436.3 \\
\hline CF2 & 32.115 & 15.589 & 2.06 & 1023.5 \\
\hline
\end{tabular}

\section{Ladder CTRL21\%F, $10 \% \mathrm{~F}^{5} \% \mathrm{~F}_{1} 21 \% \mathrm{~F} \quad 10 \% \mathrm{~F}_{5} \% \mathrm{~F}_{2}$}


Fig 1: Gel Image of the total RNA extracted from the ovary

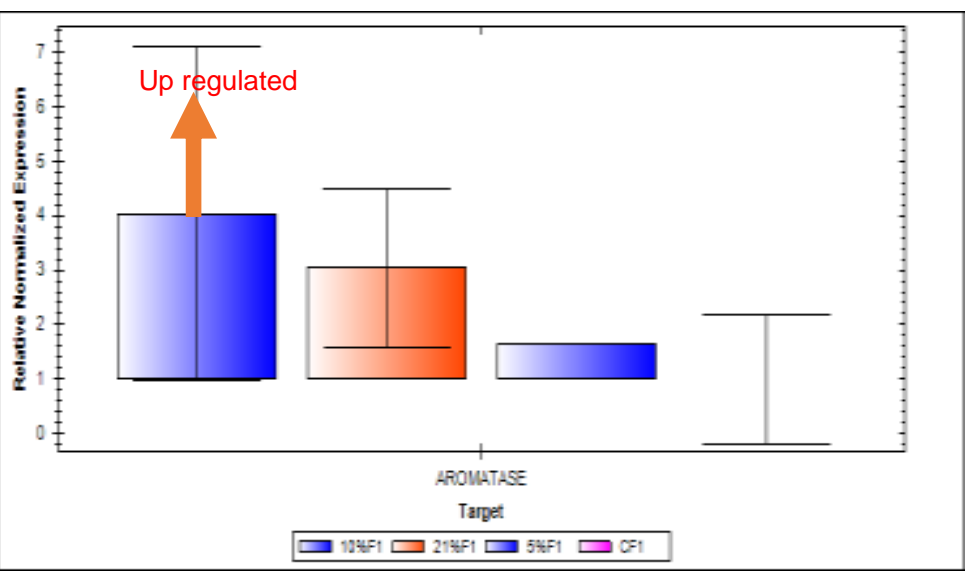

Fig 2: Plot of mRNA expression level of Aromatase in $F_{1}$ generation

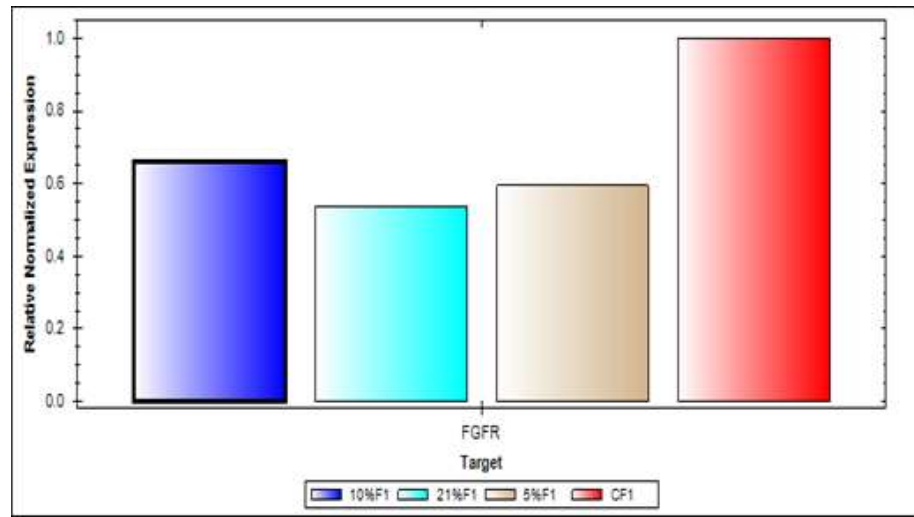

Fig 4: Plot of mRNA expression level of FGFR1 in $\mathrm{F}_{1}$ generation

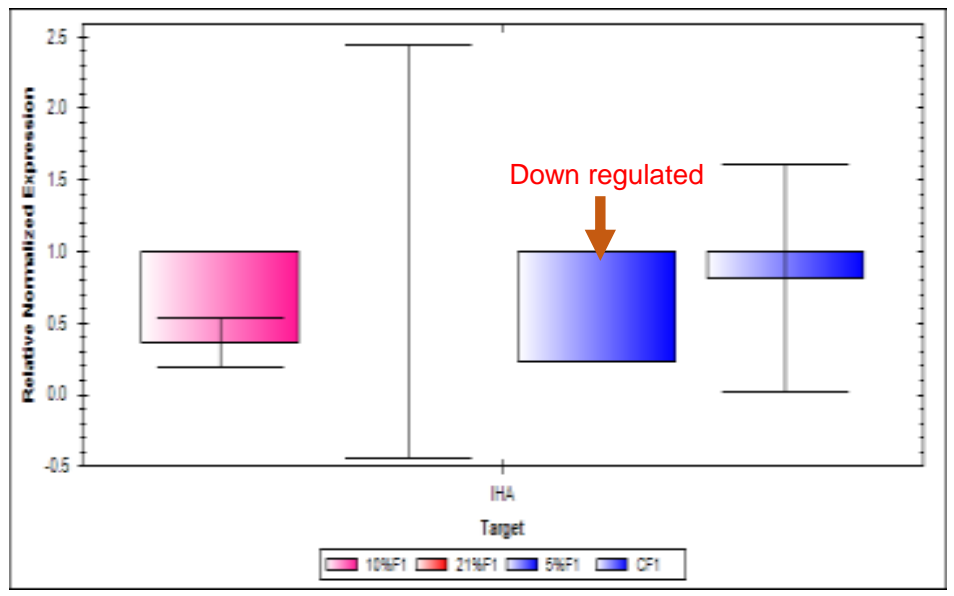

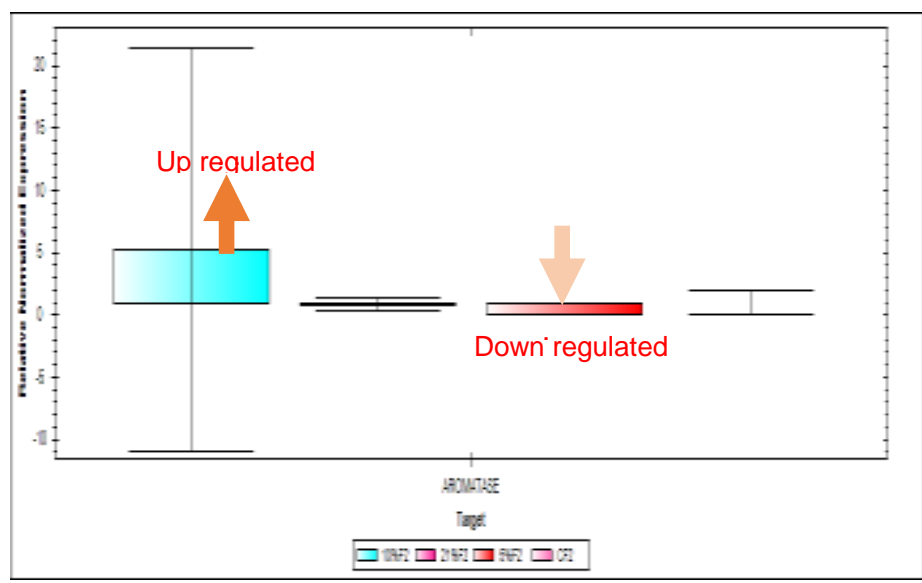

Fig 3: Plot of mRNA expression level of Aromatase in $F_{2}$ generation

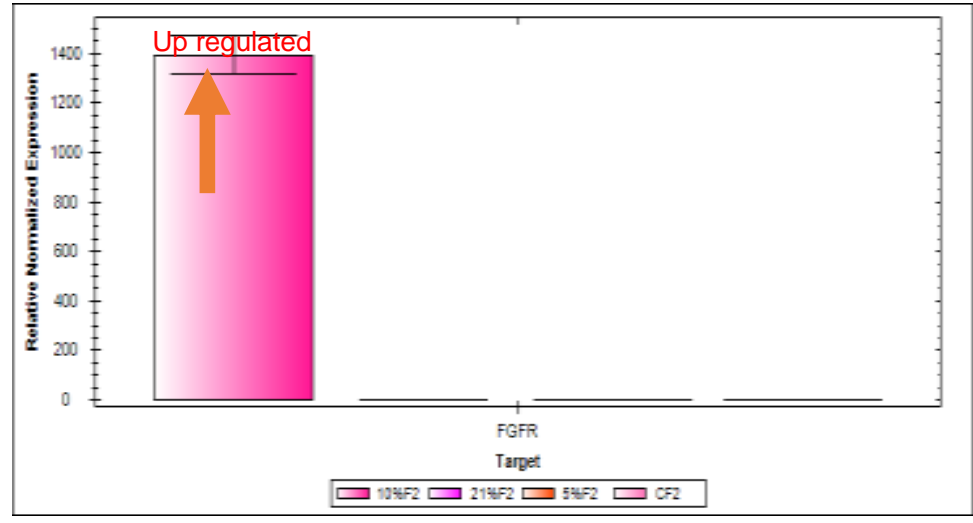

Fig 5: Plot of mRNA expression level of FGFR1 in $\mathrm{F}_{2}$ - generation

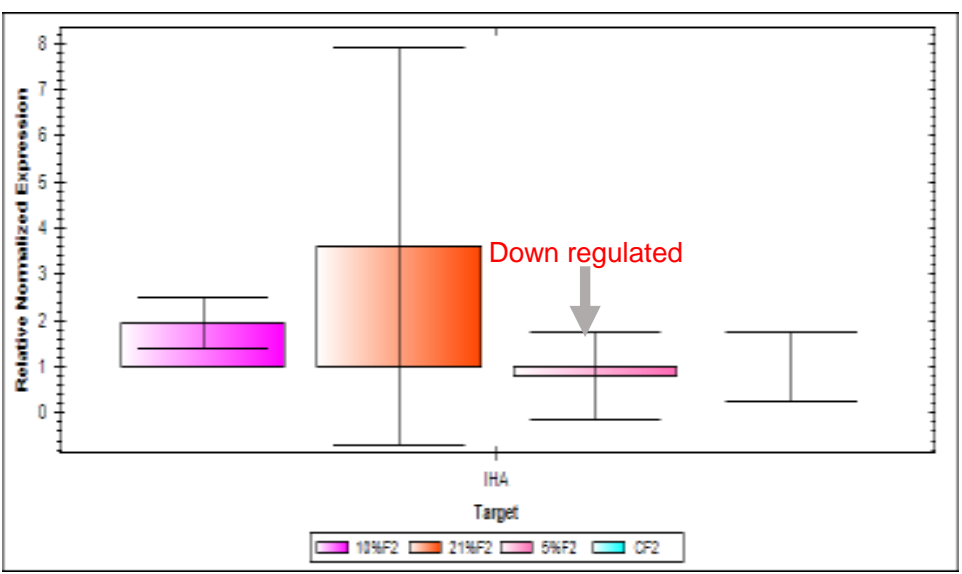


Fig 6: Plot of mRNA expression level of Inhibin-a in $F_{1}$ - generation

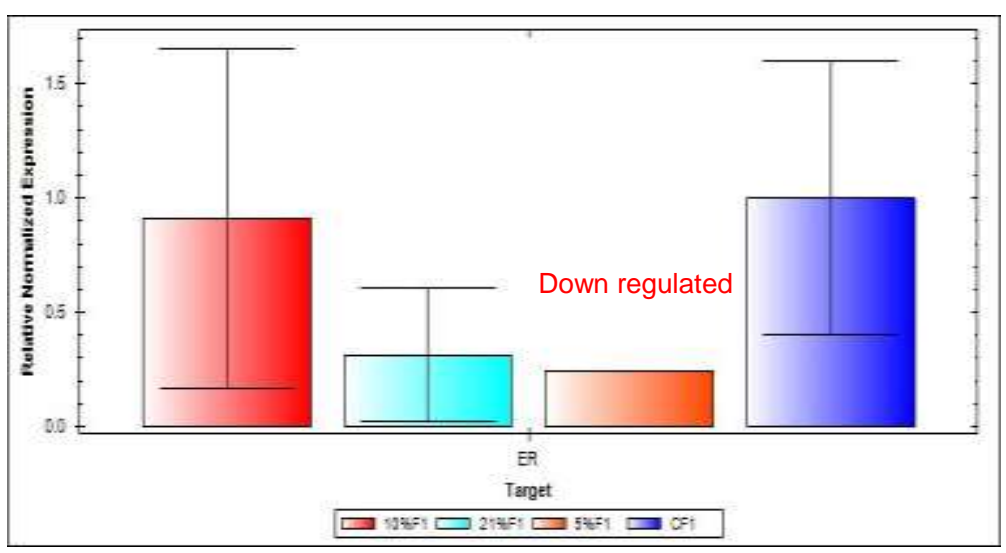

Fig 8: Plot of mRNA expression level of ERa in $F_{1}$ generation

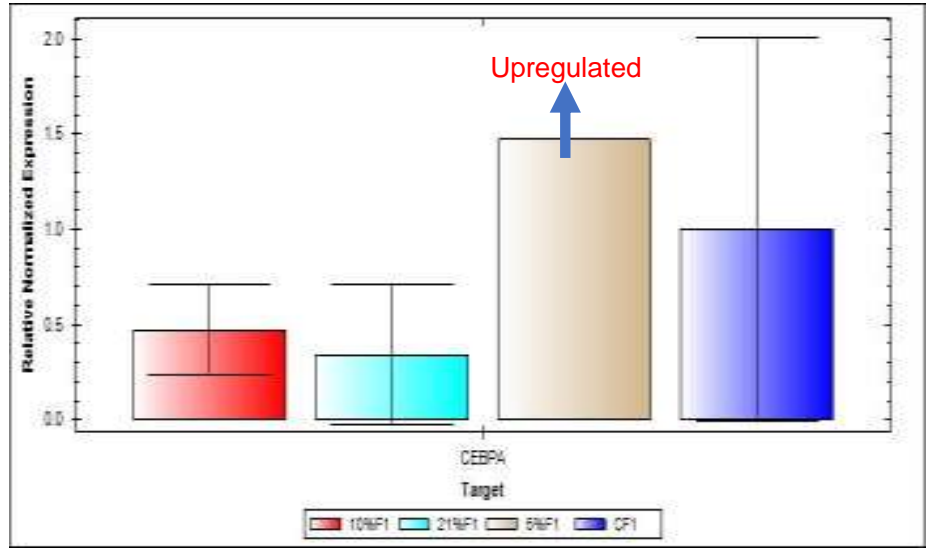

Fig 10: Plot of mRNA expression level of CEBPA in $F_{1}$ - generation
Fig 7: Plot of mRNA expression level of Inhibin-a in $F_{2}$ - generation

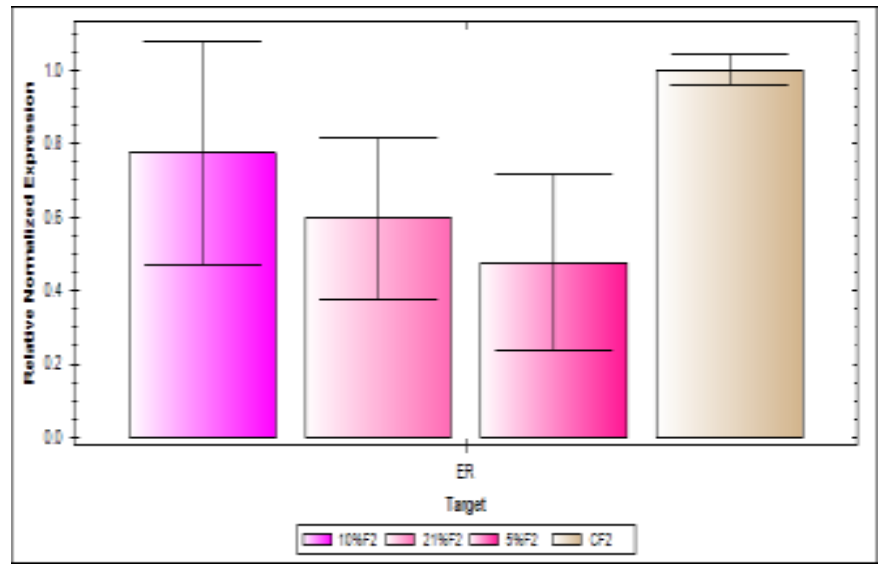

Fig 9: Plot of mRNA expression level of ERa in $F_{2}$ generation

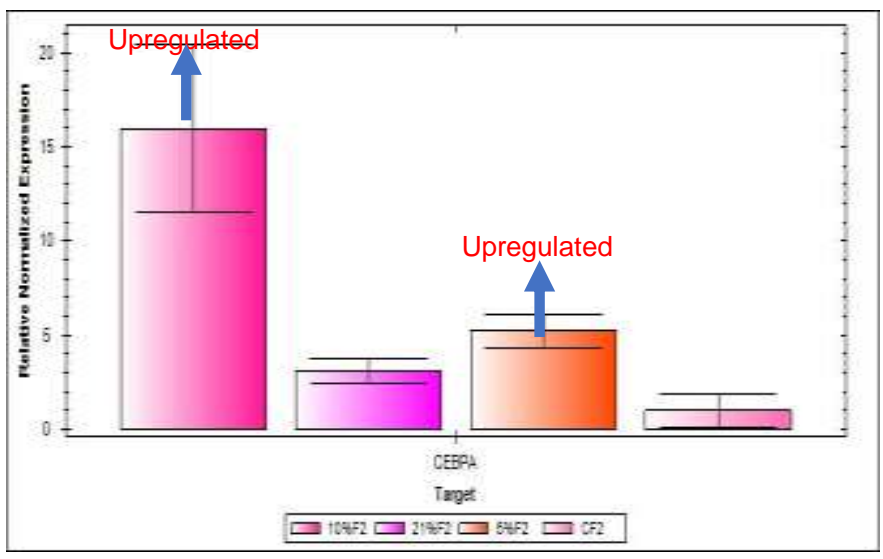

Fig 11: Plot of mRNA expression level of CEBPA in $\mathrm{F}_{2}$ - generation 


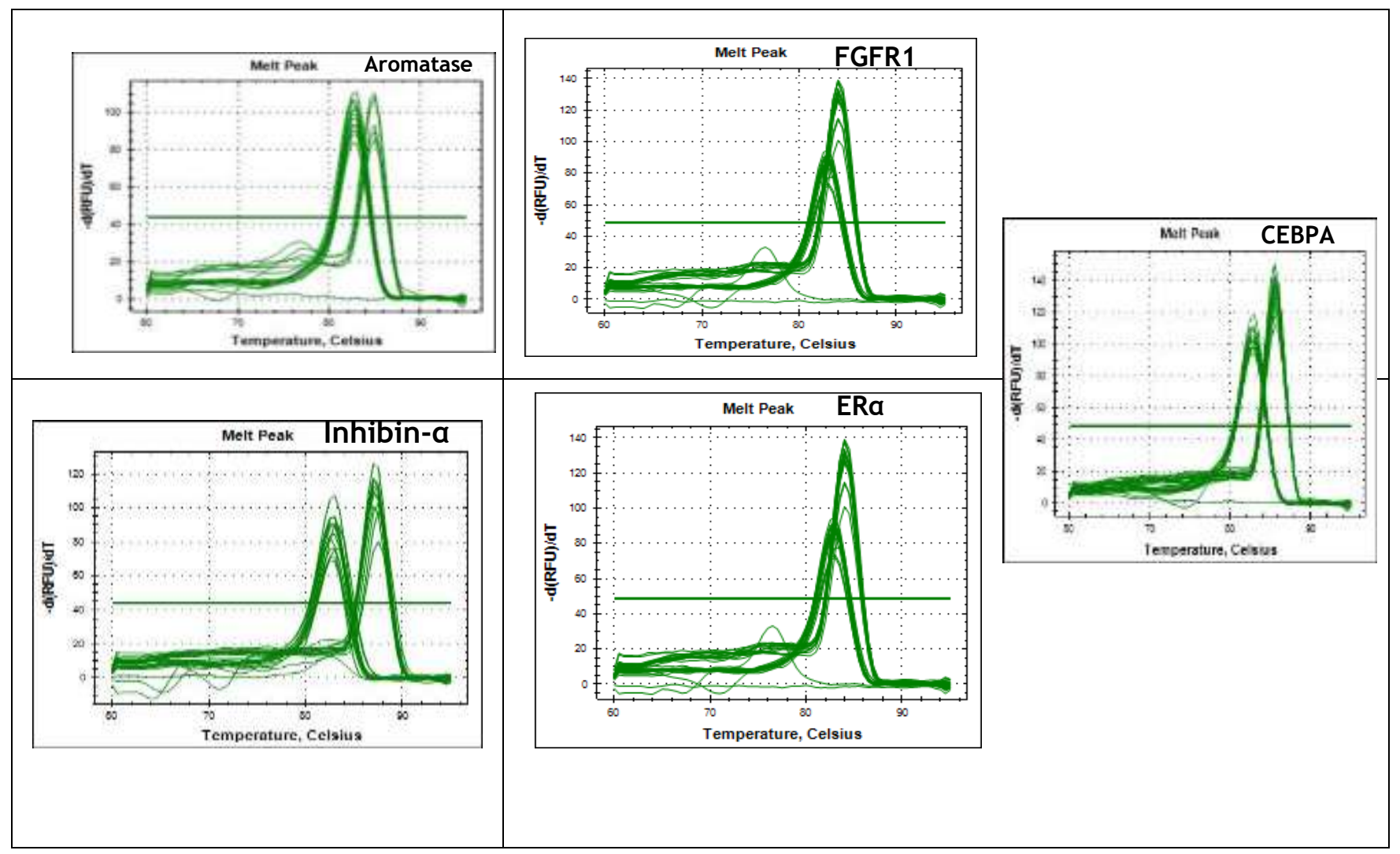

Fig 6: Melting peaks of the selected genes

\section{Discussion}

The incorrect consumption of protein or other essential nutrients in diets can lead to alteration in ovarian functions and thereby subsequently increase infertility (Silvestris et al., 2019). This study evaluates the influence of dietary protein deficiency on some key genes; Aromatase, Inhibin- $\alpha$, Cebpa, FGFR1 and Estrogen receptor alpha in the ovary as it relates to reproductive health.

Inhibin downregulation in the ovary of the severely deficient group could be underlined by increased serum follicle stimulating hormone as previously described by Li et al., (2007), that gonadal inhibin- $\alpha$ is the main peptide hormone that regulates FSH synthesis and secretion during folicullogenesis (Makanji et al., 2014). Consequently, inhibin has been applied and evaluated in clinical settings for assessment of fertility and reproductive function. Adult inhibin deficient mice have also been reported to be infertile due to severe disruption of the normal ovarian architecture as well as folliculogenesis (Makanji et al., 2014). This ovarian disruption has been linked to tumor development (Matzuk et al., 1994, 1992). The downregulation of ER $\alpha$ which is generally localized 
in the interstitial and theca cells of the ovary, especially in the 5\%PD is in accordance with previous report of Halminton et al., 2017, who reported that the repression in the expression of ovarian ER $\alpha$, is accompanied by anovulation, lack of corpora lutea, and ovarian degeneration. Lee et al., 2009 also reported a downstream effect of downregulated ER $\alpha$, as hemorrhage cyst and superovulation. This reports in line with the finding shows that protein deficiency contributes to infertility through this mechanism, and any therapeutic intervention may have to focus more on these. The normal/no change in the ER $\alpha$ expression level of the $F_{2}$ may be an adaptive response to make up for the inadequacies. FGFR1 is recorded to be among the genes that regulate the hypothalamic-pituitary reproductive axis and it has been implicated in monogenic disorders of puberty as well as developmental and reproductive complications such as dysplasia and Pfeiffer (Saxena et al., 2020).

FGFR1 gene of the P13k signaling pathway as well as the p65of NF-kB transcription factor may be involved in the regulation of apoptotic process in the ovary. The alteration in the expected/normal expression level of FGFR1 could underlie downstream deregulatory function in the ovarian granulosa cells. It has been reported by Yuan et al., 2019), that abnormal apoptosis of ovarian granulosa cells impairs follicular development and also reproductive dysfunction. Human research by Shimizu et al., (2018), stated that loss of function/downregulation of FGFR1 can induce sexual immaturity and reproductive incompetence with lowered fertility index, (Howard 2019; Topaloglu 2017). The result from this study, aligned with previous research and therefore shows that exposure to early life protein deficiency resulting in dysregulation of certain ovarian genes explains the mechanism of lowered reproductive capacity observed in the deficient subjects.

Cebpa plays pivotal role in the granulocytes, responding to inflammatory insults, as wells as gonadotropin/cAMP activation of steroidogenic Acute Regulatory protein(stARs), in response to ovulation process. Ovulation is obligatory in reproduction. Repression of ovarian specific cebpa (Fan et al., 2011) cause about 30\%reduction in ovulation although no loss in fertility response, this effect was linked to partial impairment of follicular rupture. Abnormally expressed cebpa, is a common feature of most cancers. The differential expression of cebpa in the ovary of deficient rats may be a pointer for the risk of ovarian cancer, following previous reports.

Aromatase acts in the terminal step of estrogen synthesis from androgens, it is very key to reproductive function as it modulates among others sexual behaviors and neuroendocrine synchronization for ovarian cycle. Downregulated aromatase has been associated closely with 
PCOS, through hormone buildup. (Wang et al., 2016). It is well accepted that follicle stimulating hormone controls the expression of aromatase, the negative feedback of the downregulation of the enzyme could lead to hyper androgenicity and may be downstream degeneration in the ovary (Stocco, 2008).

Conclusion: This study suggests that the mRNA expression profile of key genes is involved in the modulatory effects of dietary protein deficiency in reproductive performance from one generation to another. Report from this study, aligns with previous research and therefore distinctively shows that exposure to early life protein deficiency resulting in mal expression of certain ovarian genes explains in part the mechanism of lowered reproductive capacity observed in the deficient subjects, following persistent exposure, further emphasizing the critical nature and programming effects of early life adversity. Therefore, understanding the mechanism involved in the effect of the nutritional inadequacy could help to expand knowledge in therapeutic intervention.

\section{References}

Carlin, G., Chaumontet, C., Blachier, F., Barbillon, P., Darcel, N., Blais, A., ... Davila, A.-M. (2019). Maternal High-Protein Diet during Pregnancy Modifies Rat Offspring Body Weight and Insulin Signalling but Not Macronutrient Preference in Adulthood. Nutrients, 11(1), 96. doi:10.3390/nu11010096.

Chaumontet, C., Even, P. C., Schwarz, J., Simonin-Foucault, A., Piedcoq, J., Fromentin, G., ... Tomé, D. (2015). High dietary protein decreases fat deposition induced by high-fat and highsucrose diet in rats. British Journal of Nutrition, 114(08), 1132-1142. doi: $10.1017 / \mathrm{s} 000711451500238 \mathrm{x}$

Fan, H.-Y., Liu, Z., Johnson, P. F., \& Richards, J. S. (2011). CCAAT/Enhancer-Binding Proteins $(C / E B P)-\alpha$ and $-\beta$ Are Essential for Ovulation, Luteinization, and the Expression of Key Target Genes. Molecular Endocrinology, 25(2), 253-268. doi:10.1210/me.2010-0318

Galmiche G, Corvaisier S, Kottler ML. Aromatase gene expression and regulation in the female rat pituitary. Annals of the New York Academy of Sciences. 2006 Jul; 1070:286-292. DOI: 10.1196/annals.1317.028.

Hamilton, K. J., Hewitt, S. C., Arao, Y., \& Korach, K. S. (2017). Estrogen Hormone Biology. Nuclear Receptors in Development and Disease, 109-146. doi:10.1016/bs.ctdb.2016.12.005

Hamilton, K. J., Hewitt, S. C., Arao, Y., \& Korach, K. S. (2017). Estrogen Hormone Biology. Current topics in developmental biology, 125, 109-146.

https://doi.org/10.1016/bs.ctdb.2016.12.005 
Howard, S.R. The Genetic Basis of Delayed Puberty. Front. Endocrinol. 2019, 10, 423.

Konopka B., Szafron L., Kwiatkowska E., Podgorska A., Zolocinska A., Pienkowska-Grela B., Dansonka-Mieszkowska A., Balcerak A., Lukasik M., Stachurska A., Timorek A.,

Spiewankiewicz B., El-Bahrawy M., et al The significance of c.690G>T polymorphism (rs34529039) and expression of the CEBPA gene in ovarian cancer outcome. Oncotarget. 2016; 7: 67412-67424. Retrieved from https://www.oncotarget.com/article/11822/text/

Li Q, Graff JM, O’Connor AE, Loveland KL, Matzuk MM. SMAD3 regulates gonadal tumorigenesis. Mol Endocrinol. 2007;21:2472-2486.

Makanji, Y., Zhu, J., Mishra, R., Holmquist, C., Wong, W. P. S., Schwartz, N. B., ... Woodruff, T. K. (2014). Inhibin at 90: From Discovery to Clinical Application, a Historical Review. Endocrine Reviews, 35(5), 747-794.

Mangelsdorf DJ, Thummel C, Beato M, Herrlich P, Schütz G, Umesono K, Blumberg B, Kastner P, Mark M, Chambon P, Evans RM, (1995), The nuclear receptor superfamily: the second decade, Cell. 83(6):835-9.

Matzuk MM, Finegold MJ, Su JG, Hsueh AJ, Bradley A.-Inhibin is a tumour-suppressor gene with gonadal specificity in mice. Nature. 1992; 360:313-319.

MatzukMM, Finegold MJ, MatherJP, KrummenL, LuH, BradleyA. Development of cancer cachexia-like syndrome and adrenal tumors in inhibin-deficient mice. Proc Natl Acad Sci USA. 1994; 91:8817-8821.

Pallavi Saxena, Dibyabhaba Pradhan, Rashi Verma, Shashi Nandar Kumar, Ravi Deval \& Arun Kumar Jain (2018): Up-regulation of fibroblast growth factor receptor 1 due to prenatal tobacco exposure can lead to developmental defects in new born, The Journal of Maternal-Fetal \& Neonatal Medicine, DOI: 10.1080/14767058.2018.1529164.

Puttabyatappa, M., \& Padmanabhan, V. (2018). Developmental Programming of Ovarian Functions and Dysfunctions. Vitamins and hormones, 107, 377-422. https://doi.org/10.1016/bs.vh.2018.01.017

Richards JS, Midgley AR., Jr 1976. Protein hormone action: a key to understanding ovarian follicular and luteal cell development. Biol Reprod 14:82-94

Salvador LM, Maizels E, Hales DB, Miyamoto E, Yamamoto H, Hunzicker-Dunn M. 2002. Acute signaling by the $\mathrm{LH}$ receptor is independent of protein kinase $\mathrm{C}$ activation. Endocrinology 143:2986-2994 [PubMed] [Google Scholar]

Topaloglu, A.K.Update on the Genetics of Idiopathic Hypogonadotropic Hypogonadism. J.Clin. Res. Pediatr. Endocrinol. 2017, 9, 113-122. [CrossRef] [PubMed]

Welt, C. K. (2004). Regulation and Function of Inhibins in the Normal Menstrual Cycle. Seminars in Reproductive Medicine, 22(3), 187-193. doi:10.1055/s-2004-831894

Zhao, H., Zhou, L., Shangguan, A. J., \& Bulun, S. E. (2016). Aromatase expression and regulation in breast and endometrial cancer. Journal of molecular endocrinology, 57(1), R19R33. https://doi.org/10.1530/JME-15-0310 